\title{
Alternate-year Production Is Not Profitable in Washington Floricane Red Raspberry Systems
}

\author{
Lisa Wasko DeVetter ${ }^{1}$, Suzette Galinato ${ }^{2}$, Troy Kortus ${ }^{3}$, and \\ Jonathan Maberry ${ }^{3}$
}

ADDITIONAL INDEX WORDS. alternate-row management, alternative management systems, economic assessment, production economics, production efficiency, Rubus idaeus

SumMary. Floricane red raspberry (Rubus idaeus) produces biennial canes that are traditionally managed by annual selective removal of previously fruited floricanes and training of primocanes that will bear fruit in the next growing season. This process of pruning and training is labor intensive and costly, and growers would benefit from more economical methods of pruning and training. This 6-year project evaluated the economic viability of alternate-year (AY) production in a commercial floricane red raspberry field in northwest Washington and compared it to traditional, every-year (EY) production to assess whether the former could save costs. Despite savings from reduced chemicals, fertilizers, labor, general farm supplies, and other variable costs, the overall benefits of AY production were not enough to offset losses in revenue resulting from reduced yields under the conditions of this experiment in northwest Washington.

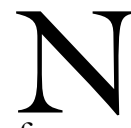
orthwest Washington leads commercial production of red raspberry ( $R$ ubus idaeus) used for processing in the United States, with 82.5 million $\mathrm{lb}$ harvested from 9200 acres in 2019 (U.S. Department of Agriculture, National Agricultural Statistics Service, 2020). Despite the scale and significance of this industry, increasing costs and decreasing availability of labor are compromising its economic viability. Floricane red rasp-

Received for publication 2 Apr. 2021. Accepted for publication 5 Aug. 2021

Published online 23 September 2021.

${ }^{1}$ Department of Horticulture, Washington State University Northwestern Washington Research and Extension Center, 16650 State Route 536, Mount Vernon, WA 98273

${ }^{2}$ IMPACT Center, School of Economic Sciences, Washington State University, 117 Hulbert Hall, Pullman, WA 99164

${ }^{3}$ Maberry Packing, LLC, 816 Loomis Trail Road, Lynden, WA 98264

Funding for this project was provided the Washington Red Raspberry Commission.

Technical support was provided by Sean Watkinson, Weixin Gan, Nadia Bostan, Huan Zhang, Yixin Cai, Qianwen Lu, Kyra Stensgaard, Clara TeVelde, and Carter DeGraw.

L.W.D. is the corresponding author. E-mail: lisa. devetter@wsu.edu.

This is an open access article distributed under the CC BY-NC-ND license (https://creativecommons. org/licenses/by-nc-nd/4.0/).

https://doi.org/10.21273/HORTTECH04864-21 berry production is particularly labor intensive, with annual selective pruning and tying of canes representing $\approx 18 \%$ of total annual costs per acre during established bearing years (Galinato and DeVetter, 2016). AY production is another method by which all canes are removed every other year in a nonselective manner, thereby possibly increasing profitability by reducing labor costs of pruning and training. AY production is practiced in more than $60 \%$ of the trailing blackberry (Rubus subgenus Rubus) fields in Oregon (Strik et al., 2007). Average yields were reduced by $20 \%$ in AY blackberry production relative to $\mathrm{EY}$ production (Strik et al., 2017), but several advantages, including decreased labor costs, reduced pesticide applications, and improved cold hardiness, contribute to its adoption (Bell et al., 1995; Bullock, 1963; Julian et al., 2009; Martin and $\mathrm{Nel}^{-}$ son, 1979; Strik, 2018).
AY production of floricane red raspberry may likewise be a more economical option for commercial operations, but minimal research on $\mathrm{AY}$ production systems has been completed in floricane red raspberry in the important production area of northwestern Washington, and economic analyses are lacking to assist growers in deciding whether to adopt this practice. In a 6-year study performed in Vancouver, WA, investigators found the yield of 'Meeker' and 'Willamette' was reduced overall by $60 \%$ in an $\mathrm{AY}$ system (Barney and Miles, 2007). However, it is unknown whether primocane suppression occurred during the study, which can impact yield potential (Duan et al., 2017). Other studies have shown floricanes yield more fruit in the absence primocanes (Sullivan and Evans, 1992; Waister et al., 1977), and more primocanes are produced in the absence of floricanes (Waister et al., 1977). The extent of this yield and growth gain can vary by cultivar (Waister et al., 1977), but has been attributed in part to leaf shading by primocanes in the EY system, leading to leaf loss on lower fruiting laterals (Wright and Waister, 1984). Yet, Fernandez and Pritts (1996) demonstrated in 'Titan' floricane raspberry that it is resilient to changes in carbon supply induced by shading, but yields still tend to be greater if prevented from full production the previous year.

Floricane raspberry has the potential to yield more on a per-cane basis in an $\mathrm{AY}$ production system and provide labor savings, which may make it more economical for northwest Washington raspberry growers challenged by rising costs of production. This project's objective was to evaluate the economic viability of $A Y$ production in a floricane red raspberry system and compare it to traditional EY production to assess whether this approach could provide cost savings for western Washington raspberry growers.

\begin{tabular}{llll}
\hline $\begin{array}{l}\text { Units } \\
\begin{array}{l}\text { To convert U.S. to SI, } \\
\text { multiply by }\end{array}\end{array}$ & U.S. unit & SI unit & $\begin{array}{l}\text { To convert SI to U.S., } \\
\text { multiply by }\end{array}$ \\
\hline 0.4047 & $\mathrm{acre}(\mathrm{s})$ & $\mathrm{ha}$ & 2.4711 \\
0.3048 & $\mathrm{ft}$ & $\mathrm{m}$ & 3.2808 \\
2.54 & inch $(\mathrm{es})$ & $\mathrm{cm}$ & 0.3937 \\
0.4536 & $\mathrm{lb}$ & $\mathrm{kg}$ & 2.2046 \\
1.1209 & $\mathrm{lb} / \mathrm{acre}$ & $\mathrm{kg} \cdot \mathrm{ha}^{-1}$ & 0.8922
\end{tabular}




\section{Materials and methods}

Treatment plots of 'Meeker' red raspberry were established in Spring 2015 at a commercial site in Whatcom County, WA (lat. $48.9^{\circ} \mathrm{N}$, long. $\left.122.5^{\circ} \mathrm{W}\right)$. 'Meeker' was selected because it is the standard cultivar for the region. The experimental design was a randomized complete block with two treatments (AY and EY production) replicated three times. Four, 700-ftlong rows of red raspberry served as a single block, and the treatments were assigned randomly to two of those rows within a block. Rows were spaced $10 \mathrm{ft}$ apart, with in-row spacing at 28 inches between plants, for a total experimental area of 1.8 acres. Plants were maintained according to commercial industry standards except for the AY treatment. During fruiting years in the AY plots (2015, 2017, and 2019), primocanes were suppressed with contact herbicides and fruit were machine harvested. All canes were subsequently removed in AY plots during the winter, after harvest, using a sickle-bar mower. Primocanes were then only grown in 2016 and 2018 (i.e., "off year" with no fruit).

Data collection began in 2015, in which a baseline enterprise budget of traditional EY red raspberry production was developed through a focus group with growers (Galinato and DeVetter, 2016). A crop enterprise budget is a financial decision-making tool that provides a means to record the income, costs, and net profit that can be generated by producing a particular crop. In Galinato and DeVetter (2016), a set of assumptions was established about raspberry production practices: scale of operation (60 acres of raspberries within a 90-acre farm operation of mixed crops), pruning and training done manually, plant protective practices (e.g., application of pesticides) done by machine, fertilizers applied by machine and through fertigation systems, machine harvest, and production specifications (row width, $10 \mathrm{ft}$; in-row spacing, 28 inches; 6 years' life of planting with 2 years of establishment and 4 years of full production; density, 2000 plants/acre). These assumptions are then used as the foundation for the fixed capital requirements of the raspberry enterprise (i.e., land, machinery), per-acre crop yield, and per-acre application rates of inputs of production (e.g., chemicals, fertilizers, labor); and the estimation of baseline costs and returns. This crop budget was the source of economic data for EY production in this study, which served as a baseline against which the AY production costs and returns were compared. For AY production, adjustments in variable costs were made in field activities associated with chemical and fertilizer applications and harvest to reflect that these costs are less during those years when there is no fruit (i.e., years 2 and 4 of AY production). During fruiting years, it was assumed that the production costs in
$\mathrm{EY}$ and AY are the same. All economic data were analyzed using Microsoft Excel (Version 2007; Microsoft, Redmond, WA).

Yield measurements were collected annually (except when the AY treatment was not fruiting) by collecting the total weight of all fruit harvested using an over-the-row harvester. Fruit were placed into flats after being initially hand-graded by two workers while on the belt of the machine harvester, and were weighed immediately. Yield data were analyzed for treatment, year, and year $\times$ treatment effects using analysis of variance in $\mathrm{R}$ (RStudio Version 1.3.1093; R Foundation for Statistical Computing, Vienna, Austria) after being evaluated for assumptions of normality and homogeneity of variance with $\alpha<0.05$. Because of the uneven distribution of standardized residuals, the response variable underwent a square transformation $\left(\Upsilon^{2}\right)$. Data were analyzed by year as a result of year $x$ treatment interactions. Original data are presented.

For the economic analysis, the EY yields from Galinato and DeVetter (2016) were used as a baseline (as mentioned earlier) and the AY yields were estimated based on their differences relative to EY yields during the first and third cropping. During the initial harvest (2015), AY yield was found to be $8 \%$ greater than EY yield, and the third AY crop yield (2019) was $37 \%$ greater than the fifth EY yield. The second AY yield (2017) was

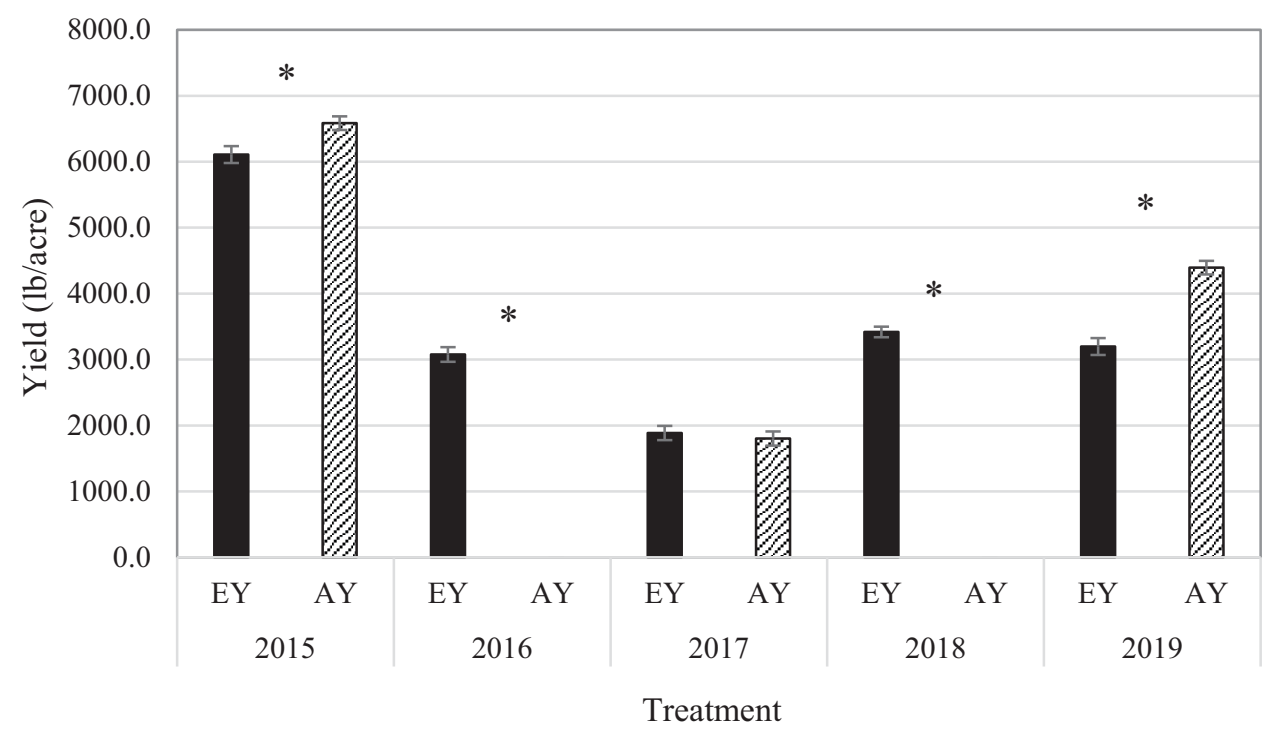

Fig. 1. Annual yield of 'Meeker' floricane raspberry grown in alternate-year (AY) or traditional every-year (EY) production systems, 2015-19. Error bars represent SE. Asterisks $(*)$ denote treatment differences within a year with $\alpha<0.05$; 1 lb $/$ acre $=$ $1.1209 \mathrm{~kg} \cdot \mathrm{ha}^{-1}$. 


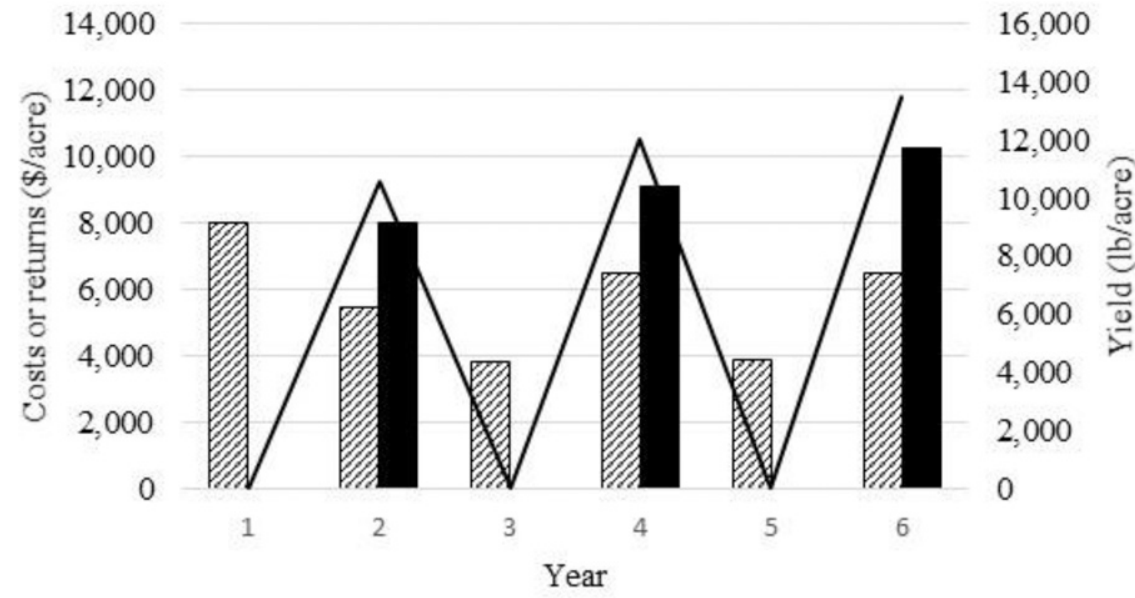

maY total costs $\mathrm{AY}$ total returns $-\mathrm{AY}$ yield

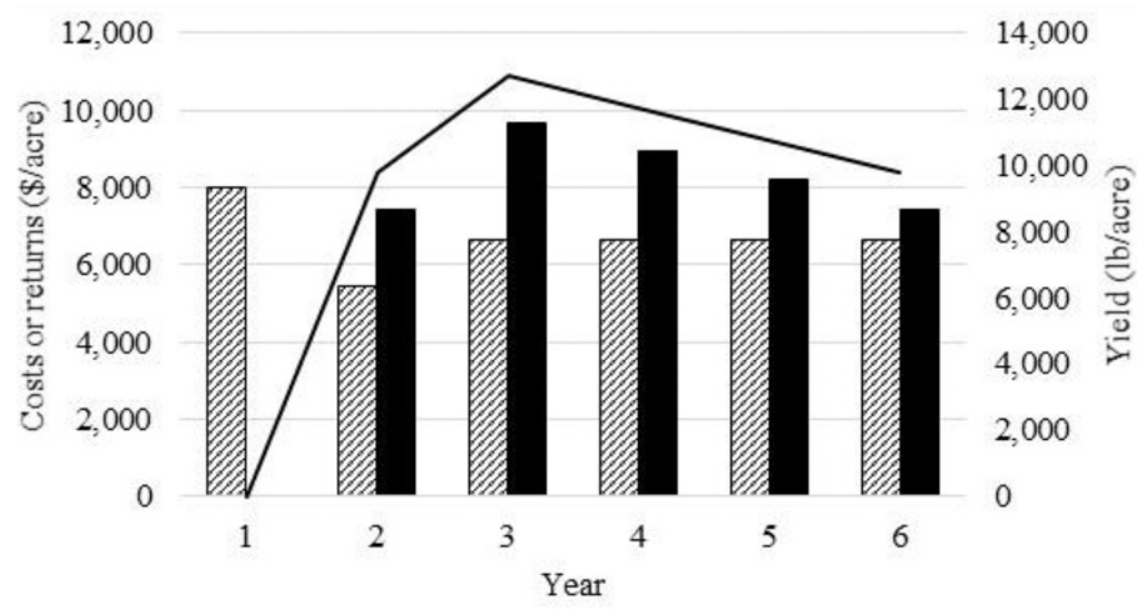

mEY total costs $=$ EY total returns $\quad$ EY yield

Fig. 2. Annual estimated costs and returns per acre of (top) alternate-year (AY; control treatment) and (bottom) every-year (EY) floricane red raspberry production systems in northwest Washington assuming a 6-year planting longevity. Baseline estimates for the EY system were made using a crop enterprise budget (Galinato and DeVetter, 2016), and the AY yields were estimated based on their differences relative to EY yields during the first and third cropping in the field study. As a result of winter injury, the second AY yield (2017) was not estimated using field data; $\$ 1 /$ acre $=\$ 2.4711 / \mathrm{ha}$.

not estimated using field data as a result of winter injury in 2017 that affected all EY and AY treatments. Because field data during the first and third cropping supported greater yields in AY than EY, it was assumed the same case applied during the second AY cropping. The average of the first and third AY crop yields was used to represent the AY crop for year 2, which was $2 \%$ greater than the third EY yield.

\section{Results and discussion}

Total yield within a year was always different $(P<0.001)$ between the two treatments except for 2017 $(P=0.257)$. Overall EY yield was 1.4 times greater relative to the AY treatment (Fig. 1) due to reduced fruit production in the AY treatment. Annual production costs and returns of the AY and EY systems are shown in Fig. 2. Returns are zero during years 3 and 5 in AY because there is no harvest during these years. However, returns are greater than costs in each of the fruiting years. Similarly, annual returns in the EY system are greater than the annual costs during all fruiting years.
Table 1 presents a side-by-side comparison of the overall economic feasibility of the two systems, considering the total costs and returns that can be expected from each system over 6 years of production on a peracre basis. In both systems, hired labor accounted for the largest cost ( $42 \%$ and $49 \%$ of total variable costs in AY and EY, respectively), whereas chemical and fertilizer costs comprised $17 \%$ of operating expenses. Total expenditures for chemicals, fertilizer, labor, general farm supplies, and other variable costs are less in the AY system by about $\$ 5255 /$ acre over 6 years than the EY system. Labor cost savings comprise about $73 \%$ of the reduced costs. Overall, the AY system has lower total operating costs than EY over the life of the planting because certain field activities are not done during nonbearing years in AY, such as application of pesticides for management of fruit rot and spotted wing drosophila (Drosophila suzukii). However, application of some fungicides and nonsystemic herbicides for primocane management still occurred and is the reason why there are still expenses for chemicals and fuel. Otherwise, expenses were the same in AY and EY during harvest years. Results show there is a net loss of $\approx \$ 6741 /$ acre over 6 years with AY production, mainly as a result of the years when there is no yield in the AY system.

Our study demonstrated potential cost savings from AY production, especially regarding labor costs. However, the overall benefits are not enough to offset the lost revenue in AY production under the conditions of this experiment. For AY production to be economically profitable, the breakeven return must be $\$ 0.95 / \mathrm{lb}$, which is $25 \%$ higher than the baseline output price. On the other hand, the breakeven AY yield over 6 years is 44,916 lb/acre.

If crop yield is increased, while holding all else the same, AY production will be as profitable as $\mathrm{EY}$ if the total AY yield over 6 years is $\approx 47,103$ $\mathrm{lb} / \mathrm{acre}$. This yield is unlikely because fields in AY production would only fruit $50 \%$ of the time. Given a 3-year average annual yield of EY production in floricane red raspberry in Washington at $8320 \mathrm{lb} /$ acre (U.S. Department of Agriculture, National Agricultural Statistics Service, 2020) and assuming 
